\title{
Depression as A Mediator Between Social Anxiety and Social Networking Addiction
}

\author{
Catherine So-kum Tang ${ }^{1,2 *}$, Masao Yogo ${ }^{3}$ \\ 'Department of Psychology, National university of Singapore, Singapore \\ ${ }^{2}$ Center for Family and Population Research, National University of Singapore, Singapore \\ ${ }^{3}$ Faculty of Psychology, Doshisha University, Kyoto, Japan
}

Article Info

\section{Article Notes}

Received: November 4, 2019

Accepted: December 16, 2019

\section{*Correspondence:}

Prof. Catherine So-Kum Tang, Department of Psychology,

9 Arts Link, National University of Singapore, Singapore;

Email: tang.catherine@nus.edu.sg.

(c) 2019 Tang CSK. This article is distributed under the terms of the Creative Commons Attribution 4.0 International License.

\section{Keywords}

Depression

Social anxiety

Social networking addiction

Depression as mediator

\section{Abstract}

According to the transactional model of stress and coping, socially anxious individuals may rely on online social networking sites (SNS) to avoid challenges and demands of "real life" social situation, leading to their addictive use of SNS. This study examined whether the association between social anxiety and SNS addiction would be mediated by depression symptoms. A total of 1015 university students in Japan completed self-administered questionnaires. Results of bivariate correlation analyses showed that social anxiety, depression, and SNS addiction were significantly related to each other. Relative to men, women reported higher levels of depression and addictive use of SNS. Results of a moderated mediation analysis showed that depression was a significant mediator between social anxiety and SNS addiction, and this mediation effect was moderated by gender. For women, social anxiety exerted an indirect effect on SNS addiction through depression. For men, social anxiety exerted both a direct effect as well as an indirect effect via depression on SNS addiction. Findings suggest that intervention programs that aim to reduce SNS addiction among young adults should include mood management as a core component, and this is particularly relevant for women. Prevention strategies for SNS addiction should also include early detection and identification of depression and social anxiety.

\section{Introduction}

Social networking sites/platforms (SNS) are Internet-based or web-based virtual communities where users interact with reallife friends as well as meet other people with common interests. SNS (e.g., Facebook and Twitter) have attracted a large number of users worldwide ${ }^{1}$. With the rapid increase of SNS users, there is also increasing concern that the use of SNS can become addictive, especially among high school and university students who are at the developmental stage when self-presentation and relation with others are the most important ${ }^{2}$.

SNS addiction refers to the addictive use of SNS accompanied by an overall sense of lack of control and other addiction symptoms such as mood modification, inability to cut down, withdrawal, tolerance, conflict, and relapse $\mathrm{e}^{5-7}$. SNS addiction is not yet formally recognized as a clinical disorder, but it is related to many adverse physical and mental conditions $\mathbf{s}^{3,4,6,8-11}$. For example, addictive use of SNS is associated with emotion regulation deficits, negative emotions of depression and anxiety, and obsessive-compulsive symptoms. Excessive time spent on SNS is also related to poor health conditions such as daytime dysfunction, poor sleep quality, ill-health symptoms (e.g., musculoskeletal pain, headache, and eye 
irritation), and unhealthy habits (e.g., sleeping late and skipping meals). Among high school and college students, SNS addiction is linked to poor academic performance. When individuals become addicted to SNS, they typically immerse themselves in the virtual communities and isolate themselves from their families and the "real" community. SNS addiction is hard to break because of the social ties that addicted individuals have with other SNS users.

\section{Proposed Moderated Mediation Model of Depression on SNS Addiction}

According to the transactional model of stress and coping $^{12}$, individuals evaluate the stressfulness of various life encounters and their abilities to determine ways of coping with these experiences. Personality traits, depressive symptoms, social support, and self-efficacy are common psychological factors that influence the appraisal and coping of stressful life events ${ }^{13}$. For the present study, the focus was on the role of depression in influencing the relationship between stress appraisal (social anxiety) and SNS addiction. Based on available literature on the topic, a moderated mediation model was proposed (Figure 1). It is noted that a mediator explains the relationship between the predictor and the dependent variable, while a moderator influences the strength of relationship among variables. The proposed model specifies that depression will mediate the effects of social anxiety on SNS addiction. Gender (moderator) will influence the strength of this mediation relationship.

\section{Social Anxiety}

Social anxiety is the persistent fear and distress of interpersonal situation that often leads to the anticipation of embarrassment or humiliation ${ }^{14}$. It is associated with negative impacts on individuals' well-being, relationship functioning, and achievements in educational and career ${ }^{15,16}$. Social anxiety is a common experience of university students whose major developmental tasks tend to focus on forming relationship and self-presentation. Socially anxious students frequently avoid interpersonal situation, adopt maladaptive coping, and seek out a "quick" way to change their apprehensive $\operatorname{mood}^{17}$. Social anxiety also associates with alcohol/drug addiction and its related negative consequences in university students ${ }^{17-19}$.

With the availability of the Internet and mobile technology in recent years, SNS has emerged as alternate outlets $\backslash$ platforms for social interaction. Socially anxious individuals may perceive SNS as more convenient, safer, and less threatening platforms to communicate and interact with people than face-to-face encounter. Over time, these individuals may become increasingly relied on SNS to avoid challenges and demands of "real life" social situation, leading to compulsive and addictive use of SNS. Indeed, research has shown that social anxiety is related to problematic Internet-related activities, especially the addictive use of SNS, in university students in both Western and Asian countries ${ }^{7,18,20-22}$.

\section{Depression}

University students typically report higher rates of

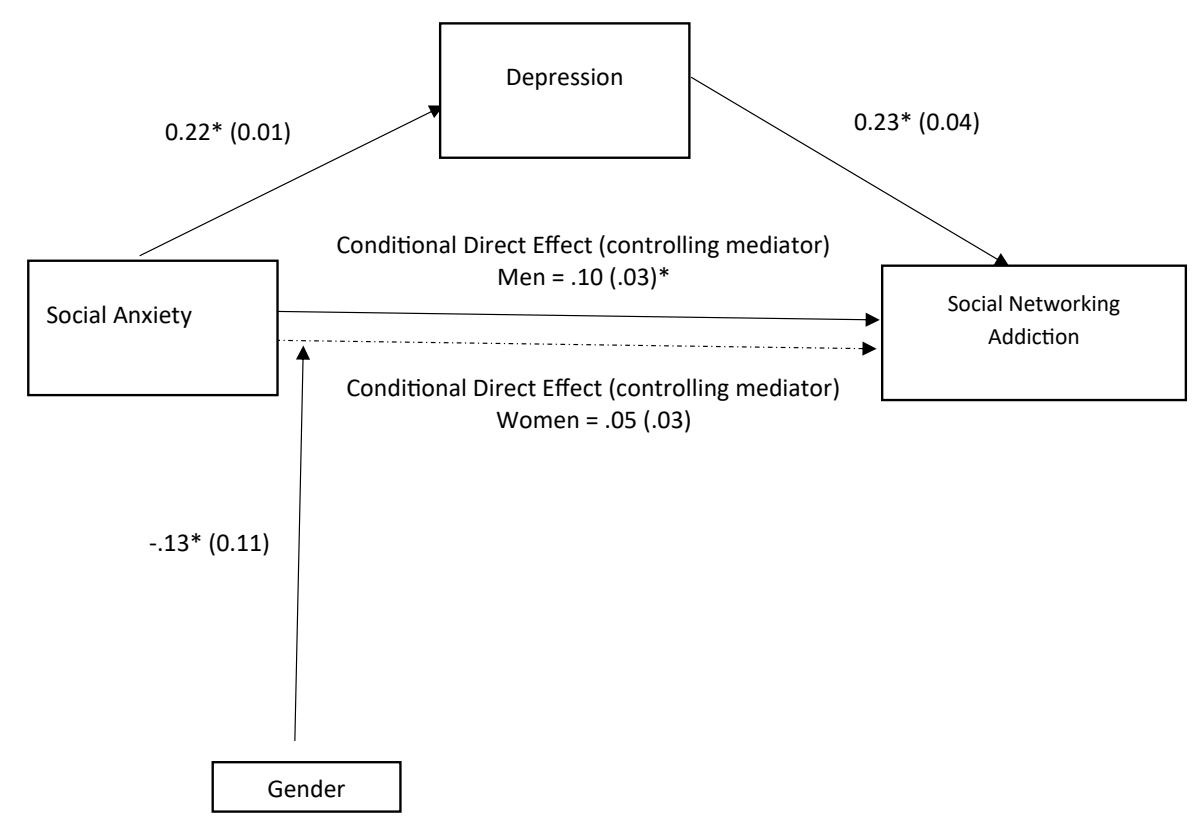

Note:

Solid arrows represent significant pathways

Values presented are coefficients and standard errors, ${ }^{*} \mathrm{p}<.05$

Figure 1: Moderated Mediation Model of Depression and Social Networking Addiction. 
depression than the general community ${ }^{23,24}$. This may be related to boredom with large blocks of unstructured time, low self-esteem with competition from peers, and feelings of being isolated and intimidated in the large campus community. According to the mood management theory ${ }^{25}$, depressed students will arrange their environment in a way that enables them to terminate or diminish bad moods while facilitating or enhancing good moods. SNS can provide opportunities for depressed students to receive immediate reassurance and mood alternation. A robust relationship has been found between SNS addiction and depression in adolescents ${ }^{8,11,26}$ as well as in college students in both Western and Asian countries $3,6,7,9,27-29$.

Depression can also function as a mediator in influencing the association between social anxiety and SNS addiction. As depressed individuals tend to be hypersensitivity to threat and hostility in the social encounter ${ }^{13}$, they commonly experience social anxiety ${ }^{16}$. Depression may increase socially anxious individuals' need to seek a quick "fix" to enhance their mood. Researchers have proposed the "problematic Internet-behavior syndrome" to refer to the increased propensity toward addiction to Internetrelated activities such as online social networking among socially anxious students who also experience depressed $\operatorname{mood}^{20}$. However, excessive reliance on SNS for mood enhancement will reduce the time and opportunities for normal social interaction and leisure activities, resulting in further reliance on SNS for mood alteration. This increasing dependency on SNS in depressive individuals may, in turn, lead to their addiction-like use of SNS.

\section{Cultural Factor and Gender}

Cultural and regional differences in SNS usage have been reported ${ }^{1}$, but these differences have been narrowed in recent years with the increasing availability of the Internet and mobile technology worldwide ${ }^{30-32}$. Overall, about 24 to $35 \%$ of Asian university students have reported being addicted to $\mathrm{SNS}^{3,6,28,33}$. Cultural/ethnic differences in the rates of social anxiety and depression are also evident ${ }^{34,35}$. Collectivistic societies, such as those of East Asia, promote an interdependence self-construal that emphasizes adapting oneself to various interpersonal and role demands in different social contexts ${ }^{36}$. Heightened sensitivity to others' opinions and evaluations is necessary for collectivistic contexts, and this may increase the vulnerability to social anxiety and depression.

In general, women relative to men report greater use of $\mathrm{SNS}^{37}$. However, there are no conclusive findings of gender differences in SNS addiction ${ }^{3,6,7,28}$. Men and women may also have different motives for SNS use and addiction. Research has suggested that women use SNS to maintain contacts with actual friends, entertainment, and passing the time; whereas men are more likely to use
SNS for making new friends, learning, and social identity gratifications $\mathrm{s}^{5,6}$. Studies on gender differences in selfreport measures of social anxiety also yield inconsistent results ${ }^{39,40}$. Some studies have found small but meaningful differences between men and women in social anxiety across countries ${ }^{41}$. Compared to men, women are also more likely to report depression symptoms and to become depressed when faced with negative life events, especially life events with interpersonal consequences ${ }^{42}$.

\section{Purposes of the Study}

Asia has the largest number of Internet and SNS users ${ }^{1}$. Existing literature on Internet-related addictions that was published in English language academic journals has focused on China, South Korea, and Hong Kong/Macau. Relatively few empirical research findings are available in other Asian countries where there are many heavy users of the Internet and SNS such as Japan, India, and Indonesia. According to the latest world statistics in $2018^{1}$, Japan is among the top countries with the highest rates for Internet penetration. Over $90 \%$ of people in Japan are online almost every day, smartphone penetration is nearly $80 \%$, and over half of the population use SNS. The "3 big" SNS in Japan are Twitter, Facebook, and Instagram; and majority users are women, students, and young adults ${ }^{43}$.

This study aimed to contribute to the knowledge gap by investigating the underlying psychological processes of SNS addiction in Japan. In particular, the mediating effect of depression on the association between social anxiety and SNS addiction was investigated. Based on the proposed moderated mediation model (Figure 1), specific hypotheses of this study were as follows:

1. SNS addiction will be related to a younger age, female gender, social anxiety, and depression.

2. Depression will mediate the association between social anxiety and SNS addiction. In other words, social anxiety will exert an indirect influence on SNS addiction through depression.

3. Gender will moderate the social anxiety-depressionSNS addiction relationship. In particular, the mediating role of depression will be stronger for women than for men.

\section{Methods}

\section{Procedure and participant characteristics}

The English questionnaire for this study was first translated to Japanese by one expert in the field who is proficient in both English and Japanese. The Japanese version was then back-translated to English by another Japanese-English bilingual expert. Modifications were then made to the Japanese translation to ensure translation equivalence. This study recruited a convenience sample of 
university students aged between 18 and 25 years old from various departments of major universities in Kyoto, Japan. The Japanese questionnaires were distributed to students at the beginning of classes and collected at the sites upon completion. Informed consents were obtained before students individually completed a set of anonymous selfadministered questionnaire without monetary reward. The questionnaires took about 20 minutes to complete, and no personally identifiable data were collected. The institutional ethics review boards of the authors' affiliated universities approved this study.

A total of 1200 questionnaires were distributed, and 1050 completed questionnaires were collected, yielding a response rate of $87.5 \%$. Questionnaires with missing data were discarded. As a result, 1015 valid questionnaires were used for data analyses. Participants included 500 men and 515 women. Their average age was 20.32 years old, with men being older than women (Means $=20.62,20.02$, respectively; $\mathrm{t}=7.73, \mathrm{p}<.001$ ).

\section{Measures}

Social networking addiction. The 6-item Bergen Facebook Addiction Scale ${ }^{38}$ was used to measure SNS addiction. This scale was based on an earlier assessment scale that measured Internet addiction ${ }^{10}$. For this study, the original term "Facebook use" was changed to "online social networking sites" to include the use of various social networking sites. Participants responded to each item with 1 as "very rarely", 2 as "rarely", 3 as "sometimes", 4 as "often", and 5 as "very often". Scoring 3 or higher on at least 4 items is categorized as having SNS addiction (Andreassen et al., 2012). The internal reliability of this scale was .80 for the present study.

Social anxiety. The 12-item short-form version of the Social Interaction Anxiety Scale ${ }^{44}$ was used to measure the level of social society in various social encounters. Participants rated the extent to which each item was characteristic of them on a 5-point Likert scale ranging from 0 "not at all" to "extremely true". For this study, the internal reliability of the scale was .89 .

Depression. The 9-item Depression Scale was adopted from the diagnostic criteria in the Diagnostic and Statistical Manual of Mental Disorders, Fifth Edition ${ }^{14}$. Participants indicated the presence of the symptoms during the last 2-week period with 0 as "never", 1 as "sometimes", 2 as "most of the day", and 3 as "nearly every day". For this study, the internal reliability of this scale was .85 .

\section{Results}

Table 1 shows descriptive statistics of major variables for all participants as well as broken down by gender. Women relative to men reported significantly higher levels of SNS addiction (Means=15.31, 13.91, $\mathrm{t}=4.30, \mathrm{p}<.001$ ) and
Table 1. Descriptive Statistics of Major Variables

\begin{tabular}{|l|l|l|l|l|}
\hline & \multicolumn{1}{|c|}{$\begin{array}{c}\text { Total } \\
(\mathbf{N}=\mathbf{1 0 1 5})\end{array}$} & $\begin{array}{c}\text { Men } \\
\mathbf{( N = 5 0 0 )}\end{array}$ & $\begin{array}{c}\text { Women } \\
\mathbf{( N = 5 1 5 )}\end{array}$ & t-test \\
\hline Age & $20.32(1.28)$ & $20.62(1.37)$ & $20.02(1.10)$ & $7.73^{* *}$ \\
\hline Social Anxiety & $13.67(9.50)$ & $13.67(9.73)$ & $13.70(9.28)$ & -0.50 \\
\hline Depression & $7.81(4.90)$ & $7.40(4.71)$ & $8.23(5.07)$ & $-2.68^{*}$ \\
\hline $\begin{array}{l}\text { Social Networking } \\
\text { Addiction }\end{array}$ & $14.61(5.22)$ & $13.91(5.17)$ & $15.31(5.18)$ & $-4.30^{* *}$ \\
\hline
\end{tabular}

Note: $* p<.01, * * p<.001$

depressive symptoms (Means=8.23, 7.81, t=2.68, $\mathrm{p}<.01$ ). There was no significant gender difference in social anxiety ( $p>$.05). Bivariate correlation analyses showed that SNS addiction was significantly associated with female gender $(\mathrm{r}=.14, \mathrm{p}<.01)$, social anxiety $(\mathrm{r}=.22, \mathrm{p}<.01)$, and depression $(\mathrm{r}=.28, \mathrm{p}<.01)$.

The hypothesized moderated mediation model (Figure 1 ) was tested with PROCESS for SPSS version 3. The direct and indirect effects of social anxiety on SNS addiction were calculated. An effect is considered to be significant if its 95\% bootstrap Confidence Intervals (CIs) from 5,000 bootstrap samples do not include zero. Figure 1 shows the coefficients of individual pathways of the hypothesized model. Pathways from social anxiety and depression leading to SNS addiction were significant and in the expected directions $(\mathrm{p}<.05)$.

Results from bootstrapping analyses showed that the predictor (social anxiety), the mediator (depression), and the moderator (gender) together accounted for a total of $10.8 \%$ of the variances in SNS addiction. The indirect effect of social anxiety on SNS addiction through depression was significant and estimated to be .05 with a $95 \%$ bootstrap CI of.03 to.07. This indicated that depression was a significant mediator between social anxiety and SNS addiction. Results also showed that gender significantly moderated the influences of social anxiety and depression on SNS addiction. For women, the conditional direct effect of social anxiety was insignificant after controlling for depression $(\beta=.05, S E=.03, t=1.90, p=.06)$, indicating that the influence of social anxiety on addictive use of SNS was fully mediated by depression. In other words, social anxiety only exerted an indirect effect on SNS addiction through depression for women. For men, the conditional direct effect of social anxiety after controlling for depression remained significant $(\beta=.15, \mathrm{SE}=.02, \mathrm{t}=2.83, \mathrm{p}<.05)$, suggesting a partial mediation. As such, social anxiety exerted both direct and indirect effects on SNS addiction for men.

\section{Discussions}

In line with the current literature, the present study found that SNS addiction among Japanese university students was related to social anxiety ${ }^{7,22,28}$ and depression symptoms $s^{3,6,7,9,28,32}$. More importantly, the mediator role of depression between social anxiety and SNS was supported. 
In particular, depression fully mediated the influence of social anxiety on SNS addiction for women. For men, social anxiety exerted a direct influence on SNS addiction, as well as an indirect influence via depression.

The above results provided some support that the "problematic Internet-behavior syndrome" can be extended to understand SNS addiction among Japanese university students. This syndrome refers to the increased propensity to Internet-related addictions in individuals who experience a multitude of emotional disturbances ${ }^{20}$. This syndrome is most relevant among Japanese female students, as depression fully mediated the influence of social anxiety on SNS addiction. It can also partially explain higher rates of SNS addiction found in women even though the two genders do not differ on social anxiety ${ }^{39}$. It may be that women tend to be more vulnerable to experience a depressed mood, and thus have increased sensitivity to potential stressful social encounter. They may be more motivated than men to turn to SNS for mood alteration ${ }^{16}$. Studies have also suggested that individuals who rely on SNS predominantly to satisfy their social or escape needs are at a greater risk for developing an addiction than those who rely on the SNS for self-presentation ${ }^{22,45}$.

The present study has several limitations. First, data were collected from students in universities in a major city in Japan. It remains unclear the extent to which the present results can be extended to the entire university student population in Japan and other countries. It is also unclear whether the present results can be generalized to young adults of similar age who are not attending universities. Second, this study used self-report instruments without external validation of SNS usage and clinical assessment of social anxiety and depression. Third, this study assumed the homogeneity of various SNS without examining their specific nature. There is also a lack of information on motives in using SNS. Finally, the cross-sectional study design renders it difficult to establish causative factors leading to SNS addiction and its maintenance over time. Data were collected at a single time point, and common method variance may also inflate the observed associations among variables. Nevertheless, the present findings contribute to the understanding of relevant psychological processes underlying SNS addiction among Japanese university students.

\section{Conclusions}

Social anxiety and depression are common experiences among university students. SSN addiction is a mental health condition with many aversive consequences, and this requires public attention and intervention. Socially anxious students, particularly those with depressive symptoms, are vulnerable to develop SSN addiction. This study points to the importance of early identification of social anxiety and depression among university students to prevent the occurrence of SSN addiction. The present results also implicated that intervention programs for SNS addiction, especially programs that target women, should include mood management as a core component.

\section{References}

1. Internet Usage in Asia Internet users Facebook subscribers \& Population Statistics for 35 countries and regions in Asia. Internet World and Statistics 2018 https://www.internetworldstats.com/ stats3.htm

2. Arnett J. Emerging adulthood: A theory of development from the late teens through the early twenties. Am Psychologists. 2000; 55: 469480 .

3. Andreassen CS. Online social networking site addiction: A comprehensive review. Current Addict Report. 2015; 2: 175-184.

4. Griffins MD, Kus DJ, Demetrovics Z. Social networking addiction An overview of preliminary findings. In K.P. Rosenberg \& L.C. Feder (eds.), Behavioral addictions: Criteria, evidence, and treatment 119114 London Academic Press 2014.

5. Kuss DJ, Griffins MD. Online social networking and addiction: A review of the psychological literature. Int J Environ Res \& Public Health. 2011; 8: 3528-3552.

6. Kuss DJ, Griffins MD. Social networking sites and addiction: Ten lessons learned. Int J Environ Res \& Public Health. 2017; 14: 311-317.

7. Ryan T, Chester A, Reece J, et al. The use and abuses of Facebook: A review of Facebook addiction. J Behav Addict. 2014; 3: 133-148.

8. Keles B, McCrae N, Grealish A. A systematic review: the influence of social media on depression, anxiety and psychological distress in adolescents. Int J Adol \& Youth. 2019. https://doi.org/10.1080/026 73843.2019.1590851

9. Rosen LD, Whaling K, Rab C, et al. Is Facebook creating iDisorder? The link between clinical symptoms of psychiatry disorders and technology use, attitudes and anxiety. Computers Human Behav. 2013; 29: 1243-1254.

10. Young K. Internet addiction The emergence of a new clinical disorder. CyberPsych \& Behav. 1998; 3: 237-244.

11. Li JB, Mo PK, Lau JT, et al. Online social networking addiction and depression: the results from a large-scale prospective cohort study in Chinese adolescences. J of Behav Addict. 2018; 7: 689-696.

12. Lazarus RS, Folkman S. Transactional theory and research on emotions and coping. Eur J Personality. 1987; 1: 141-169.

13. Folkman S, Lazarus RS. Stress processes and depressive symptomology. J Abnormal Psychol. 1986; 95: 107-113.

14. American Psychiatric Association. Diagnostic and Statistical Manual of Mental Disorders (DSM-5). Arlington VA American Psychiatric Association 2013.

15. Heerey EA, Kring AM. Interpersonal consequences of social anxiety. J Abnormal Psychol. 2007; 116: 125-134.

16. Stein MB, Kean YM. Disability and quality of life in social phobia: Epidemoloic findings. Am J Psychiatry. 2000; 157: 1606-1613.

17. Schry AR, White SW. Understanding the relationship between social anxiety and alcohol use in college students: A meta-analysis. Addict Behav. 2013; 38: 2690-2706.

18. Prizant-Passal S, Schnechner T, Aderka I. Social anxiety and Internet use-A meta-analysis: What are we missing? Comput Human Behav. 2016; 62: 221-229.

19. Villarosa MC, Madson MB, Ziegler-Hill V. Social anxiety symptoms and 
drinking behaivors among college students: The mediating effects of drinking motives. Psychol Addict Behav. 2014; 28: 710-718.

20. De Leo JA, Wulfert E. Problematic Internet use and other risky behaviors in college students: An application of problem-behavior theory. Psychol Addict Behav. 2013; 27: 133-141.

21. Koo HJ, Kwon JH. Risk and protective factors of Internet addiction: A meta analysis of empirical studies in Korea. Yonsei Med J. 2014; 55: 1691-1711.

22. Lee-Won RJ, Herzog L, Sung GP. Hooked on Facebook The role of social anxiety and the need for social assurance in problematic use of Facebook. Cyberpsych Behav Social Networking. 2015; 18: 587574.

23. Gastelum J, Weiss L, Vanderford J. Evidence for a mental health crisis in gradute education. Nature Biotechnolgy. 2018; 36: 282-284.

24. Ibrahim AK, Kelly SJ, Adams CE, et al. A systematic review of studies of depression prevalence in university students. J Psychiatric Res. 2013; 47: 391-400.

25. Zillman D. Mood management through communication choices. Am Behav Sc. 1988; 31: 327-340.

26. Raudsepp L, Kais K. Longitudinal associations betweem problematic social media use and depressive symptoms in adolescent girls. Preventive Med Rep. 2019; 15. https://doi.org/10.1016/j. medr.2019.100925

27. Mak KK, Jeong J, Lee HK, et al. Mediating effect of Internet addiction on the association between resilience and depression among Korean university students: A structural equation modeling approach. Psychiatry Investigation. 2018; 15: 962-969.

28. Tang CS, Koh YW. Online social networking addiction among college students in Singapore: Comorbidity with behavioral addiction and affective disorder. Asian J Psychiatry. 2017; 15: 175-178.

29. Yoon S, Kleinman M, Mertz J, et al. Is social network site usage related to depression? A meta-analysis of Facebook-depressoin relations. J of Affect Disord. 2019; 248: 65-72.

30. Jackson LA, Wang JL. Cultural differences in social networking site use: A comparative study of China and the United States. Comput Human Behav. 2013; 29: 910-921.

31. Shostya A. The use of time among college students. A US-China comparison. Int J of Educ. 2015; 7: 195-208.

32. Tang CS, Koh YW, Gan Y. Addiction to Internet use, online gaming, and online social networking among young adults in China, Singapore, and the United States. Asia Pacific J of Public Health. 2017; 30: 673-682.

33. Yu S, Wu AMS, Pesigan I. A. Cognitive and psychosocial health risk factors of social networking addiction. Int J of Mental Health Addict. 2016; $14: 550-564$.

34. Lau AS, Fung J, Wang SW, et al. Explaining elevated social anxiety among Asian Americans: Emotional Attunement and a Cultural Double Bind. Cultural Diversity \& Ethnic Minority Psychol. 2009; 15: 77-85.

35. Okazaki S. Sources of ethnic differences between Asian American and White American college students on measures of depression and social anxiety. J of Abnormal Psychol. 1997; 106: 52-60.

36. Markus HR, Kitayama S. Culture and the self: Implications for cognition emotion and motivation. Psychol Rev. 1991; 98: 224-253.

37. Andreassen CS, Torsheim T, Brunborg GS, et al. Development of a Facebook Addiction Scale. Psychol Rep. 2012; 110: 501-517.

38. Feingold A. Gender differences in personality: A meta-analysis. Psychol Bulletin. 1994; 116: 429-456.

39. 37. Greenwood S, Perrin A, Duggan M. Social media update 2016. Pew Res Center. 2016. http://www.pewinternet.org/2016/11/11/socialmedia-update-2016/

40. Hirai M, Vernon LL, Clum GA, et al. Psychometric properties and administration measurement invariance of social phobia symptom measures Paper-pencil vs internet administrations. J Psychopathology Behav Assess. 2011; 33: 470-479.

41. Caballo VE, Salazar IC, Irurtia MJ, et al. Differences in social anxiety between men and women across 18 countries. Personality Individual Differences. 2014; 64: 35-40.

42. Hyde, Mezulis A, Abramson LY. The ABCs of depression: Integrating affective, biological, and cognitive models to explain the emergence of the gender difference in depression. Psychol Rev. 2008; 115: 291-323.

43. Social media in Japan 2018 Current stage and upcoming trends. Plus Alpha Digital 2018. https://plusalphadigital.com/social-media-injapan/

44. Peters L, Sunderland M, Andrews G, et al. Development of a short form Social Anxiety (AIAS) and Social Phobia Scale (SPS) using nonparametric item response theory The SIAS- 6 and the SPS- 6 . Psychol Assess. 2012; 25: 26-226.

45. Weiser EB. The functions of Internet use and psychological consequences. CyberPsych Behav. 2001; 4: 723-743. 